\title{
LA JURISPRUDENCIA DE LA CORTE SUPREMA SOBRE EL RECURSO DE INAPLICABILIDAD (1981-1985)
}

\author{
Raúl Bertelsen Repetto \\ Profesor de Derecho Constitucional \\ Facultad de Derecho - Universidad Católica de Valparaíso \\ S U M A R I O
}

Introducción. 1. Precepto legal aplicable a la gestión que se sigue ante otro tribunal. II. Precepto legal contrario a la Constitución: a) temporalidad de la oposición entre ley y Constitución; b) Carácter que debe tevestir la oposición entre ley y Constitución; c) La inconstitucionalidad de forma y el recurso de inaplicabilidad. III. Disposiciones constitucionales que han fundamentado declaraciones de inaplicabilidad a partir de 1981. rv. Conclusiones.

\section{I N T R O D U C C I 6 N}

1. En el trabajo que la profesora Luz Bulnes Aldunate presentara a las xiII Jornadas de Derecho Público celebradas en Concepción en 19821, junto con examinar los antecedentes y la regulación del recurso de inaplicabilidad en el actual texto constitucional, tuvo ocasión de examinar la jurisprudencia emanada de la Corte Suprema sobre el particular en los dos primeros años -aproximadamente- de vigencia de la Constitución de 1980.

La invitación para estas xvi Jornadas de Derecho Público indicaba como tema de las mismas la aplicación de la Constitución Política de 1980, con especial referencia a la aplicación que ha tenido en el ámbito jurisprudencial. Al escoger, entonces, como objeto de esta po-

${ }^{2}$ Luz Bulnes Aldunate, El recurso de inaplicabilidad en la Constitución de 1980, en "XIII Jornadas de Derecho Público", Universidad de Concepcion. Concepción, 1983, 13-27. 
nencia el estudio de la jurisprudencia de la Corte Suprema sobre el recurso de inaplicabilidad entre 1981 y 1985 , he querido responder con ella a la sugerencia formulada, tratando un tema que considero de gran interés para apreciar la vigencia efectiva de la Constitución y, también, aprovechar la oportunidad para ocuparme nuevamente de un problema con el que me había enfrentado años atrás al examinar las decisiones por medio de las cuales la Corte Suprema efectuaba el control de constitucionalidad de las leyes bajo la Constitución de I925².

Algo más de cuatro años de actividad de la Corte Suprema a partir de marzo de 1981, no es, por cierto, un tiempo suficiente para que surja una jurisprudencia abundante y completa sobre los distintos aspectos que plantea el recurso de inaplicabilidad y sobre los diversos preceptos de la Constitución que pueden incidir en su fallo, porque estamos ante un recurso que por su propia naturaleza es mucho menos frecuente en su utilización que el de otros medios de control de constitucionalidad, como es el caso del recurso de protección ${ }^{3}$. Es inevitable, por consiguiente, que las decisiones de la Corte Suprema sólo han podido ocuparse de determinados problemas, razón que explica que algunos puntos han sido objeto de cierto desarrollo, mientras que otros no hay todavía decisiones.

2. Es sabido que la normativa constitucional sobre el recurso de inaplicabilidad, tanto en el texto. de 1925 (artículo 86 , inciso 29) como en el de 1980 (artículo 80), exige que el precepto legal cuya constitucionalidad se cuestione tenga aplicación en el "juicio" o "gestión" seguido ante otro tribunal, de acuerdo con los términos utilizados por uno y otro constituyente. La exigencia es perfectamente comprensible y acorde con el tipo de control de constitucionalidad admitido en estos preceptos, pues. la declaración de inaplicabilidad - como su nom-

'Lo hice en forma breve en mi Control de constitucionalidad de la ley. Editorial Jurfdica de Chile. Santiago de Chile. 1969, 165.171, y con más detalle para una materia especffica en And́lisis de los recursos de inaplicabilidad por inconstitucionalidad interpuestos en contra de preceptos legales de reforma agraria, Centro de Investigación de Recursos Naturales (CIREN). Escuela de Derecho Universidad Católica de Valparaíso. Valparaíso. 1970.

"El número de recursos de inaplicabilidad que se presenta cada año ante la Corte Suprema oscila en torno a los veinte; en cambio, ante la sola Corte de Apelaciones de Santiago se han presentado en los últimos años varios centenares de recursos de protección. 
bre lo indica- es un control de normas legales que inciden o pueden incidir en la decisión de un caso real y actual.

Sobre la noción de aplicabilidad de los preceptos legales cuestionados a la gestión que se sigue ante un tribunal diverso a la Corte Suprema, existe después del 11 de marzo de 1981 -fecha en que entró a regir la Constitución de $1980-$, una decisión de aquélla, si bien corresponde a un asunto iniciado antes que entrara en vigencia la actual Constitución.

Es el caso de Ana Correa Prado y otros, fallado el 8 de julio de 1981. La Corte Suprema rechazó el recurso, "porque el precepto que se dice inconstitucional no tiene aplicación posible en el pleito deducido por los recurrentes, porque legisla sobre el destino de los predios expropiados, es decir, inscritos a nombre de la Corporación de la Reforma Agraria, y, por consiguiente, mientras los demandantes no obtengan sentencia ejecutoriada que les restituya el que fue objeto de la expropiación, no pueden pretender que la Constitución proteja su eventual derecho de propiedad, ni que los afecte un decreto ley aplicable sólo a los predios expropiados por la entidad mencionada"4.

El criterio sustentado por la Corte Suprema resulta acertado. El faIlo de la acción ejercitada, que perseguía la restitución de un predio agrícola expropiado, no dependía en su decisión de la aplicación del precepto legal cuestionado, por lo cual entrar a analizar si resultaba o no opuesto a alguna norma constitucional era irrelevante. Es cierto que la Corte no exige para recurrir de inaplicabilidad, plena seguridad en que la disposición legal objetada recibirá aplicación, pues estima que basta la posibilidad que ello ocurra para entrar a analizar el fondo del recurso, pero en la especie existía certeza en su no aplicación, de modo que una eventual declaración de inaplicabilidad carecía de interés ${ }^{5}$.

II. P R E C E P T O LE G A L C O N T RA R I O A L A C O NSTIT U C I $6 \mathrm{~N}$

3. "Cualquier precepto legal", en lenguaje de la Constitución de

"Revista de Derecho y Jurisprudencia, tomo 78 (1981) n-5, 113, consid. 89

'En 1953, al fallar el recurso de inaplicabilidad interpuesto por la Sociedad Industrial y Ganadera de Magallanes, la Corte Suprema sostuyo que "de los términos amplios en que está concebido el precepto constitucional 
1925, o "todo precepto legal", como reza la de 1980, con tal que sea "contrario a la Constitución", permite una declaración de inaplicabilidad. Aparentemente, entonces, no habrta razón para que surgieran problemas nuevos sobre el particular, luego de la entrada en vigencia de la Constitución de 1980. Sin embargo, la nueva situación constitucional y las caracteristicas del ordenamiento jurídico fundamental han determinado que antiguos problemas cobren una dimensión distinta y que aparezcan otros que antes no existian en torno a la determinación de qué tipo de contradicción entre un precepto legal y la Conscitución permite sustentar un recurso de inaplicabilidad.

Tres asuntos distintos merecen ser destacados en este tema: la temporalidad de la oposición entre la ley y la Constitución, el carácter que debe revestir esta oposición y el problema de la inconstitucionalidad formal.

\section{a) Temporalidad de la oposición entre la ley y la Constitución}

4. La aparición de un nuevo texto constitucional, sobre todo si se trata de un ordenamiento jurídico completo y no parcial, da origen a un problema que no se presenta en épocas de gran estabilidad institucional: el de las leyes anteriores a la Constitución que resultan opuestas a ésta una vez que ella entra en vigencia. El problema es particularmente delicado en Chile, pues a partir de 1973 y hasta 1980 hay materias en que ha habido una sucesión de varios textos con rango constitucional: la Constitución de 1925; Decretos Leyes anteriores.y posteriores al Decreto Ley 788, dictados en ejercicio tácito o expreso de la potestad constituyente; las Actas Constitucionales de 1976 y.la Constitución de 1980. ¿Qué efectos producen estos textos sobre las normas legales anteriores? ¿Las derogan tácitamente? ¿O es necesario obtener la declaración de inaplicabilidad para que el precepto legal anterior a la Constitución y contrario a ésta, deje de aplicarse?

5. Con algunos matices y escasas excepciones, la posición de la Corte Suprema ha sido que el precepto legal contrario a la Constitu-

resulta que para promover ente recurso sblo se exige la posibilidad, no la certeza, de que una ley inconstitucional pueda ser aplicada en la especie debatida". (2DJ tomo 50 (1953) $\mathrm{n}$ - 1479 , consid. 79 
ción cuya inaplicabilidad se solicita, debe ser posterior a la fecha en que entró a regir la Constitución de 1980. Entre diversos fallos en este sentido puede citarse el recaído en el recurso de inaplicabilidad interpuesto por Miguel Valech Escándar: "Este recurso ha denunciado a esta Corte Suprema una supuesta contradicción entre una norma legal y la Constitución Política que nos rige, que no puede dar cabida a una cuestión de inconstitucionalidad ni a un recurso de inaplicabilidad, sino que a un problema de supervivencia o derogación de una ley, lo que es propio de la competencia de los jueces del fondo"6.

La oposición que se denuncia en el recurso de inaplicabilidad debe ser únicamente la que existe entre un precepto legal posterior a la norma constitucional que le es contraria, siempre que esta norma esté vigente a la fecha en que se presenta el recurso, pues, a su vez, la norma constitucional podría haber sido derogada por otra disposición constitucional posterior.

"Como lo ha resuelto reiteradamente este Tribunal-recuerda la Corte Suprema en Alberto Lacoste Gauthier-, para que pueda ser admitido a tramitación un recurso de inaplicabilidad por inconstitucionalidad de algún precepto legal, éste debe encontrarse en oposición con el texto constitucional vigente a la época en que se reclama la inaplicabilidad?.

Este criterio es, indudablemente, el que más se aviene con el principio que afirma que las leyes de derecho público rigen in actum, el cual ha obligado a contemplar disposiciones constitucionales transitorias cuando se desea que una ley o una norma constitucional, anteriores y contrarias al nuevo texto, sigan en vigencia. También está de acuerdo este criterio con una de las bases de la institucionalidad relativas al Estado de Derecho, que afirma que los preceptos de la Constitución obligan a toda persona, institución, grupo o integrante

RDJ tomo 79 (1982) II-5, 176, considerando 39. En nota a esta sentencia se cita otros recursos en que la Corte Suprema sustentó el mismo criterio. Sin embargo, en un interesante voto de minoria suscrito por el Presidente Retamal y el Ministro Erbetta, recaído en el recurso de inaplicabilidad presentado por José Guerra Bastías contra el Decreto Ley 2.695 de 1979 , se sostuvo que la Corte Suprema podia entrar a pronunciarse sobre la inaplica. bilidad de una ley anterior que contraviene a la Constitución posterior (Fallos del Mes 325 (1985) 865).

${ }^{T_{R D J}}$ tomo $78 \mathrm{II} \cdot 5.246$, consid. 79. También en FM 276 (1981) 516. 
de un organo estatal (articulo 69, inciso 29 de la Constitución de 1980).

6. Sin embargo, la Corte Suprema ha entrado en ocasiones a ponderar por la via del recurso de inaplicabilidad si un precepto legal anterior a la Constitución de 1980 se opone a alguna disposición de ésta.

Uno de estos casos es el planteado en el recurso presentado por Fernando Torres Maillard. Los preceptos legales.objetados por una posible pugna con el artículo 73 , inc. 19 de la Constitución, eran el artículo 19 transitorio, inc. 39, del Decreto Ley 1.078 de 1975 y los artículos 918, inciso 19, 919 y 922 del Código de Procedimiento Civil.

La Corte Suprema, aunque desechó en definitiva el recurso, entró al fondo del mismo sin declararlo inadmisible, analizando si los preceptos legales citados eran o no opuestos a la facultad exclusiva que tienen los Tribunales "de conocer las causas civiles y criminales, de resolverlas y de hacer ejecutar lo juzgado"8.

La Corte, a pesar que no lo afirma de manera explícita, parece entender en este fallo que cualquiera oposición existente entre un precepto legal y una norma constitucional puede ser examinada a través del recurso de inaplicabilidad, sin que tenga importancia qué disposición jurídica es anterior. "Es el recurso de inaplicabilidad $\rightarrow$ se dice en el considerando 10- el medio establecido precisamente para encarar y resolver si alguna de esas leyes ordinarias contradice o no una determinada regla constitucional, en términos de oposición total y decisiva".

Más interesante aún, por el matiz que introduce, es una sentencia de abril de 1984, que desechó la inaplicabilidad solicitada por la Sociedad Agricola La Granja Lida. en un juicio que tenía contra al Banco Hipotecario y de Fomento Nacional, respecto al articulo 98 de la Ley General de Bancos (Decreto Ley 2.099), por una presunta oposición con el artículo 19 NQ 3, incisos 19 y 59 de la Constitución de 1980.

Aunque se trataba de un precepto legal de 1978 objetado como contrario a la Constitución de 1980, la Corte no declaró inadmisible el recurso aduciendo que se estaba ante un problema de derogación

TM 284 (1982) 249. 
de leyes que corresponde a los jueces del fondo, sino que entró a conocer del recurso de inaplicabilidad. Pero, a diferencia del caso Ta rres Maillard, planteó el problema de la anterioridad de los preceptos legales impugnados ${ }^{9}$.

Así; en el considerando 50, la Corte Suprema recordó su tesis tradicional que establece la improcedencia del recurso de inaplicabilidad para solicitar la no aplicación de preceptos legales anteriores a los de la Constitución a los que resultan opuestos y declaró improcedente un capítulo del recurso presentado, el que sostenía la contradicción del articulo 98 de la Ley General de Bancos con el artículo 19 № 26 de la Constitución.

No obstante y para el mismo precepto legal, entró a analizar su oposición con el artículo 19 No 3 de la Constitución. Para hacerlo, tuvo presente que los incisos 10 y 50 del mismo provienen del Acta Constitucional No 3 de 1976 (artículo 10, No 3, incisos 10 y 50), de donde los tomó en términos idénticos la Constitución de 1980. "Por lo cual -razona la Corte- puede afirmarse con toda propiedad que ellas (las disposiciones constitucionales) han estado en vigor, con invariable nivel constitucional y sin solución de continuidad, desde que comenzó a regir la aludida Acta Constitucional, vale decir, desde el 18 de septiembre de $\mathbf{1 9 7 6}$. Por consiguiente, es fuerza convenir que las anotadas normas, aunque figuren hoy en la Carta de 1980, son sin embargo anteriores al actual artículo 98 de la Ley General de Ban. cos, que data de 1978, en que el Decreto Ley 2.099 le dio su nuevo texto; y siendo asi no cabe aplicar a su respecto la tesis de que se ha hecho mérito" (Considerando 69).

Esta innovadora doctrina de la Corte Suprema atiende al contenido de la norma constitucional, más que al texto del que forma parte, para aceptar la admisibilidad del recurso de inaplicabilidad. En verdad, resulta dificil en un caso como el que es objeto de análisis mantener el criterio tradicional sustentado por la Corte, y que al ser el mismo el precepto constitucional que existe en uno y otro texto, el vigente antes y el que entró a regir después que lo hiciera la disposición legal atacada, no se divisa una razón válida para negar la procedencia del recurso de inaplicabilidad, sin perjuicio que pudiera plan-

${ }^{\circ}$ TM 305 (1984) 87. 
tearse también ante los jueces del fondo el problema de la derogación tacita de la key.

La doctrina admitida por la Corte Suprema permite indudablemente examinar mediante el recurso de inaplicabilidad la posible oposición de preceptos legales anteriores a la Constitución de 1980, con esta, pero sólo cuando la Constitución reproduce disposiciones constitucionales tomadas de textos anteriores que estaban vigentes a la fecha en que entró en vigor el precepto legal impugnado. ¿Qué ocurrirá, en cambio, cuando la Constitución de 1980 no haya contemplado idénticas, sino similares o parecidas disposiciones que el texto constitucional anterior? Es difícil dar una respuesta, pero, si los cambios fueran meramente de redacción de modo que el alcance de la norma permaneciera idéntico, parece que igualmente debiera admitirse el recurso de inaplicabilidad.

7. Casos verdaderamente atípicos en este tema de la temporalidad de la oposición entre ley y Constitución son dos fallos recaídos sobre preceptos contenidos en decretos leyes cuya vigencia antes o después de la Constitución de 1980 es muy discutible.

El primero de ellos es el recurso de inaplicabilidad, aceptado por la Corte Suprema, interpuesto por la Sociedad Urbanizadora de la Costa Ltda. (Urcost Ltda.) contra el artículo 19 del Decreto Ley 3.652 por ser opuesto al articulo 19 NQ 24 de la Constitución.

El Decreto Ley 3.652 fue publicado en el Diario Oficial del 11 de marzo de 1981, fecha en que entro a regir la Constitución de 1980, lo cual generó una situación especialísima que no se planté por la Corte Suprema: o bien el precepto legal objetado es anterior a la Constitución, caso en que el recurso de inaplicabilidad debió ser declarado inadmisible; o bien, es anterior la Constitución de 1980 al precepto legal, caso en que sf procedé declarar la inaplicabilidad del mismo, lo que hizo efectivamente la Corte en una sentencia muy ininteresante por la doctrina de fondo sustentada, pero sin advertir lo peculiar, que resultaba dictar decretos leyes luego que entra en vigor I. Constitución'10.

El segundo de estos casos atípicos es el que se refiere al recurso de inaplicabilidad deducido contra el Decreto Ley 3.655, datado el 10 de marzo de 1981 y publicado en el Diario Oficial del día 17 del mis-

moJ tomo 79, II-5, I; 8M 278 (1982) 607. 
mo mes. La mayoría de la Corte, en un fallo que ha sido discutido, consideró que el mencionado Decreto Ley, "por haber sido acordado y promulgado con sujeción a los preceptos constitucionales a su fecha vigentes, adquirió plena y formal existencia de ley antes de entrar a regir la Carta Fundamental de 1980, esto es, el 11 de marzo de 1981"11.

\section{b) Carácter que debe revestir la oposición entre la ley y la Constitución}

8. La Corte Suprema ha tenido un criterio muy estricto para admitir la oposición de una ley a la Constitución. No se ha aceptado la declaración de inaplicabilidad de un precepto legal sino cuando aparece de manifiesto su contradicción con la Constitución. Así lo sostuvo años atrás -en 1950- en forma tajante:

"Para que pueda prosperar un recurso de inaplicabilidad, es indispensable que exista una completa y perfecta contradicción entre una ley constitucional y una ordinaria; es decir, que ambas no puedan coexistir entre sí por contener normas o fines jurídicos que se contrapongan al aplicarse a un négocio determinado ${ }^{12}$.

$Y$, en forma más restrictiva, afirmaría la propia Corte Suprema en 1971, que en el recurso de inaplicabilidad "no corresponde hacer sino una comparación concreta y objetiva entre los preceptos constitucionales y legales que se formulan como antinómicos. Es decir, se trata de un recurso de derecho estricto" 13 .

La Constitución de 1980, no obstante, contiene numerosos preceptos en que se establecen exigencias de justicia para que la actuación del Iegislador y de las autoridades gubernativas y administrativas sea constitucional. Así, por ejemplo, el artículo 19 No 2, inc. 20, establece que " $n i$ la ley $\mathrm{ni}$ autoridad alguna podrán establecer diferencias arbitrarias", y el artículo 10 inc. 30 , prescribe que "el Estado reconoce y ampara a los grupos intermedios a través de los cuales se organi-

I"RDJ tomo 81 (1984) II-4, 19, consid. 11. FM 304 (1984) 44. Para su critica ver Alejandro Silva Bascuñán, Sobre una importante sentencia, en "El Mercurio" (Santiago de Chile) 10-5-84, A 2.

1"RDJ tomo 47 (1950) II-1, 166.

${ }^{13}$ RDJ tomo $68(1971) 11-1,30$, consid. 29. 
2a y estructura la sociedad y les garantiza la adecuada autonomia para cumplir sus propios fines especificos".

In estos y otros casos en que los preceptos constitucionales contienen exigencias de justicia que debe respetar el legislador, la Corte Suprema al conocer de los recursos de inaplicabilidad tendra que analizar si los preceptos legales tachados de inconstitucionales acatan n no dichas exigencias, para lo cual no bastará una mera comparación objetiva entre el precepto constitucional y el legal, sino tendrá que ponderar si el contenido de este último se ajusta a los criterios de justicin exigidos por las normas constitucionales, criterios cuyo significado y alcance tendrá que precisar. El recurso de inaplicabilidad, por consiguiente, exige ahora un mayor desarrollo doctrinal y no puede ser calificado siempre de recurso de derecho estricto.

En el recurso Torres Maillard, al examinar una de las constitucionalidades planteadas, para rechazarla, se tuvo presente que "una y otra norma pueden coexistir separadamente, ya que propugnan fínes jurfdicos distintos, que no se contraponen al aplicarse a un determinado asunto"14.

Bsta valoración de los fines perseguidos por la norma constitucional y la ley que, en verdad, como lo demuestra el fallo antes citado de 1950 no estaba excluidx; pero no era frecuente, representa, indudablemente, un gran avance en el desarrollo que puede efectuarse de la Constitución vía recurso de inaplicabilidad y abre interesantes perspectivas a la doctrina y a la jurisprudnecia.

En Gasman Castro15, al declarar inaplicable el artículo 40 NQ 10 de la ley 18.045 sobre mercado de valores por tres causas distintas, la Corte Suprema tuvo que determinar sobre todo el significado de la autonomía que la Constitución reconoce y garantiza a los grupos in. termedios en el articulo 10, inciso 39. Tal forma de razonar supone un avance notable en la transformación del recurso de inaplicabilidad en una forma de control de constitucionalidad de la ley más creativa.

c) La inconstitucionalidad de forma y el recurso de inaplicabilidad

9. El recurso de inaplicabilidad presentado por la Saciedad Agricole - Maderera Neltume Ltda., aceptado por la Corte Suprema en abril

Mne 284 (1982) 249, consid. 49.

ins 314 (1985) 764 . 
de 1985, suscitó nuevamente el tema de si los vicios de inconstitucionalidad de forma de que adolezca una ley, pueden fundamentar una declaración de inaplicabilidad ${ }^{16}$.

La Corte, razonando extensamente sobre el particular (considerandos 39 a 99), mantuvo su criterio tradicional sostenido de modo invariable bajo la vigencia de la Constitución de 1925, en el sentido que no procede declarar la inaplicabilidad por vicios de forma.

La Corte Suprema, para sustentar su decisión, analizó tanto el texto del artículo 80 de la actual Constitución como la historia de su establecimiento. Sin entrar a discutir en detalle la argumentación del organo contralor, que no me parece del todo convincente, deseo llamar la atención sobre un par de problemas que pueden aparecer con cierta frecuencia y a los que es necesario encontrar una solución que proporcione seguridad juridica.

Uno de ellos es el que se refiere al tipo de leyes que debe regular una materia dada. Cuando esté vigente integramente la Constitución de 1980, surgirán probablemente dudas acerca de si una materia que fue regulada por ley común no es acaso propia de ley de quórum calificado, de ley orgánica constitucional o de reglamento autónomo. En cualquiera de estos casos, se estará ante un precepto legal, pero no tal vez ante el precepto adecuado para el asunto regulado en atención a la materia de éste. Tal disconformidad, ¿será admitida como fundamento de un recurso de inaplicabilidad o se considerará que este recurso no es la vía por la que corresponde plantear el caso?

El otro problema es el de la derogación o modificación de los Decretos Leyes con rango constitucional, anteriores o posteriores al Decreto Ley 788 que dictó normas sobre el ejercicio del Poder Constituyente. ¿Cómo deben ser modificados dichos Decretos Leyes? El recurso de inaplicabilidad de la Sociedad Agricola y Maderera Neltume I.tda., sostenía que debían serlo por una ley de reforma constitucional y por eso postulaba la inconstitucionalidad formal de una ley común como lo es la ley 17.998. La Corte Suprema, al eludir un pronunciamiento sobre los vicios de forma deja esta cuestión pendiente ${ }^{17}$.

${ }^{18} \mathrm{FM} 317$ (1985) 85.

'TEl fallo fure aprobado con una prevención del Presidente Retamal, quien no aceptó los considerandos $6^{\circ}, 78^{\circ}, 8^{\circ}$ y $99^{\circ}$, relativos a la inconstitucionalidad de forma, pero, por coincidir con las decisiones de la sentencia 
II. DTSOBICIONEB CONETTUCTONALES Q UE AAN UNBA ENTADO DECLA.

RACIONES DE INAPLICABILIDAD

A PRTIR DE 1981

10. En el examen que hemos efectuado de las decisiones de la Corte Suprema a partir de marzo de 1581 y que llega hasta diciembre de 1985 al momento de redactar en forma definitiva esta ponencia, encontramos que las sentencias emanadas de aquella que declaran inaplicable algún precepto legal por ser contrario a la Constitución, en parte mantienen criterios anteriores, pero también abren nuevos derroteros.

\section{a) Protección de la propiedad de derechos adquiridas}

11. La aceptación por parte de la Corte Suprema de la protección constitucional de los derechos que tuvieran la calidad de adquiridos fue admitida por la Corte Suprema bajo textos constitucionales anteriores, que eran menos claros en su letra que el actual de 1980, para aceptar la existencia de una propiedad sobre derechos.

Así ocurrió cuando regía el texto originario de la Constitución de 1925 sobre derecho de propiedad, la que aseguraba a todos los habitantes de la República en el artículo 10 No 10, inc. 19 "la inviolabilidad de todas las propiedades sin distinción alguna" para añadir luego en el inc. 29 que nadie podia, salvo el caso de sentencia judicial o de expropiación por utilidad pública, "ser privado de la de su dominio, ni de una parte de ella, o del dereche que a ella tuviere".

La misma situación se dio luego de la reforma constitucional contenida en la ley 16.615, de 20 de enero de 1967, que sustituyó completamente el artículo 10 NQ 10 de la Constitución. Este, en lo pertinente, dispuso que se aseguraba "el derecho de propiedad en sus diversas especies" y que "nadie puede ser privado de su propiedad sino en virtud de ley general o especial que autorice la expropiación por causa de utilidad pública o de interés social".

Con mayor claridad aún aparece la propiedad sobre derechos en la

que ve referfan a in inconstitucionalidad de fondo, no. emitio pronunciamiento respecto de aquella. 
Constitución de 1980, que en esta parte sigue al Acta Constitucional No 3 de 1976. El artículo 19 No 24 asegura a todas las personas "el derecho de propiedad en sus diversas especies sobre toda clase de bienes corporales o incorporales" (inciso 19) y después añade (inciso 3 \%), que "nadie puede, en caso alguno, ser privado de su propiedad, del bien sobre que recae o de alguno de los atributos o facultades esenciales del dominio, sino en virtud de ley general o especial que autorice Ia expropiación por causa de utilidad pública o de interés nacional, calificada por el legislador".

12. Después de marzo de 1981 hay varias decisiones de la Corte Suprema que reiteran y desarrollan su doctrina tradicional. Un grupo de estas decisiones está conformado por los fallos que han declarado inaplicable la letra c) del artículo 37 de la ley 18.091, por infringir un derecho incorporal de propiedad consistente en gozar de una determinada bonificación, de la que resultaban inconstitucionalmente privados por el precepto legal citado que tenía un aparente carácter de ley interpretativa, pero que era realmente una ley con efecto retroactivo. Me refiero a los recursas interpuestos por Isabel Flies Steffens, Fernando de la Cerda Tapia y otros, y Ricardo Roldán Alvarado ${ }^{18}$.

Sociedad Urbanizaciones de la Costa Ltda. es más original19. Aquí se extiende la protección constitucional del derecho de propiedad a la que existe sobre los derechos litigiosos. Al hacerlo, la Corte Suprema precisó primeramente "que el derecho a pretender el pago de lo que se habría pagado indebidamente es un derecho incorporal que deducido en juicio constituye una acción mueble, capaz de convertirse en un derecho de dominio sobre una cosa corporal si un fallo judicial lo reconoce". Pues bien, "ese derecho - -según sostuvo la Corte- tiene garantia constitucional y no puede una ley abrogarlo sino cumpliendo la norma que para el caso de expropiación establece el artículo 19 No 24 de la Constitución Política" (considerạndo 8).

De ahí que "las acciones de las partes... siendo como son derechos que ellas han adquirido en virtud de la ocurrencia de hechos regidos

${ }^{1 s_{\mathrm{RDJ}}}$ tomo 80 (1983) $\mathrm{H}-5,90$; RDJ tomo $81 \mathrm{rI}-5,16$ y $\mathrm{FM} 305$ (I984) 100 , I FM 319 (1985) 323, respectivamente. Sobre el tema de los derechos adquiridos ver Eduardo Soto Kloss, Los derechos adquiridos en el Derecho Priblico chileno. (Réquiem para una inepcia doctrinaria), en kDJ tomo 81 (1984) I, 13-23.

${ }^{10_{\text {RDJ J }}}$ tomo $79 \mathrm{n}-5,1 . \mathrm{FM} 278$ (1982) 607. 
por la ley, no pueden ser desvirtuados por otra ley porque los protege el articulo 19 No 24 de la Constitución para ser declarados a favor de uno u otro de los contendientes por la judicatura, único poder autorizado para ello por esa misma Ley Fundamental" (considerando 11).

Por tal razón, el artículo 19 del Decreto Ley 3.652 resulta contrario a la Constitución desde el momento que declara "lfcitos y ajustados a derecho" los cobros cuyo pago indebido se discutía en el juicio con ocasión del cual se interpuso el recurso de inaplicabilidad. Ello, porque abroga los derechos ejercidos por los litigantes "y enerva el que tienen para que el fallo final favorezca a cualquiera de ambos, reconociéndole su dominio sobre un crédito por la cantidad pagada" (considerando 14).

Fácil es advertir de la lectura de los considerandos transcritos, que la argumentación desarrollada por la Corte Suprema para aceptar la inaplicabilidad solicitada servirá de base en el futuro para atacar la constitucionalidad de otros preceptos legales que, pendiente un proceso, influyan en la decisión de la cuestión controvertida, aduciendo que han afectado un derecho que tiene la calidad de adquirido.

b) Derecho a gozar de la propiedad

13. Una novedad en la jurisprudencia constitucional representa la declaración de inapljoabilidad del artículo 40 NQ 10 de la ley 18.045 sobre mercado de valores, porque priva a la sociedad afectada -la Bolsa de Valores de Santiago- de su derecho a repartir dividendos. "Ese precepto de la ley -sostuvo la Corte Suprema en el considerando 11 de su sentencia - atenta contra el derecho de la Bolsa de Valores a gozar de los frutos de sus capitales y tareas. repartiendo entre sus componentes esos frutos civiles que son los dividendos, porque la tesis de que en todo caso el precepto impugnado solo demora el reparto que se puede producir cuando la sociedad Bolsa de Valores se liquide, no legitima la privación que ella sufre mientras existe como ente social"20.

La fundamentación de la inaplicabilidad se encuentra aqui en la aposición del precepto legal impugnado con el artículo 19 NQ 24 de la Constitución que asegura el derecho de propiedad, el cual, resulta

mis 314 (1985) 764, especialmente consid. 9. 10, 11 y 12. 
vulnerado porque una de las facultades esenciales del dominio como es el derecho de goce, no es respetado. Es, sin duda, un ejemplo elocuente de la potencialidad que está encerrada en la actual garantía constitucional sobre derecho de propiedad.

\section{c) Igualdad ante la ley}

14. La garantía constitucional de igualdad ante la ley, aunque podría haber sido objeto de un rico desarrollo jurisprudencial, no lo tuvo durante la vigencia de la Constitución de 1925. Desde 1976, cuando se dicta el Acta Constitucional No 3 y ahora en la Constitución de 1980, no sólo se protege "la igualdad ante la ley" sino que el propio constituyente extrae como consecuencia que "ni la ley ni autoridad alguna pueden establecer diferencias arbitrarias" (articulo 19 No 2, inc. 20 de la Constitución).

Gasman Castro marca aquí, también, una nueva tendencia jurisprudencial ${ }^{21}$. Un precepto legal, el artículo 40 No 10 de la ley 18.045, aplicable sólo a un tipo de sociedades comerciales - las bolsas de valores- se consideró que vulneraba "la igualdad ante la ley haciendo una discriminación arbitraria entre dicha sociedad y las demás sociedades comerciales, todas éstas capacitadas potencialmente para repartir dividendos" (considerando 8).

No fue obstáculo, en este caso, la generalidad relativa del precepto legal que es aplicable a cualquier bolsa de valores y que antes se consideraba suficiente para respetar la igualdad ante la ley, sino que se estima que el hecho diferenciador - ser bolsa de valores- no es relevante para deducir a partir de él un trato legal diverso al que reciben otros tipos de sociedades comerciales, trato que, en consecuencia, significa una arbitrariedad inadmisible frente a la citada garantia constitucional.

d) Ejercicio exclusivo de atribuciones jurisdiccionales por los tribunales

15. Sociedad Agricola y Maderera Neltume Ltda.22, recurso al que antes nos hemós referido con motivo del problema de la inconstitu.

${ }^{2}$ FM 314 (1985) 764.

F 517 (1985) 85, especialmente ccnsiderandos 10 a 23, sobre la incons. titucionalidad de fondo. Notese que, a diferencia de Gasman Castro, en 
cionalidad de forma, es un caso notable de inaplicabilidad que merecerfa un análisis más detallado que el que aquí puede prestársele, por la complejidad del problema derivado de la reforma agraria que trata, por el acopio de antecedentes utilizados para fallar y por la argumentación desarrollada.

En sintesis, la Corte Suprema estimó en el considerando 21 de su rentencia: "Que la ley en cuestión (articulos 19 y 29 de la ley 17.998), invocando la facultad del legislador de explicar o interpretar la ley de un modo generalmente obligatorio que el texto constituciosal vigente le confiere, no legisló para establecer o crear el derecho mediante una norma general, impersonal y abstracta, sino para dar solución a un caso concreto, sometido a la resolución de los Tribunales, detérminando cuál es el derecho aplicable en esos casos, de tal manera que no ejerció la función legislativa que la Constitución lo faculta, sino que una función judicial, propia de los Tribunales".

El fallo no significa que, a juicio de la Corte Suprema, el legislador, no pueda en caso alguno dictar normas que vayan a tener aplicación en un proceso pendiente, pero sí que únicamente puede hacerlo cuando se trate de normas que efectivamente tienen un carácter general. En cambio, cuando aparezca que la ley elaborada está dirigida a solucionar casos concretos conocidos por los tribunales, no resulta conforme a la Constitución. Es un avance en una materia que en el pasado ha dado origen a más de un recurso de inaplicabilidad.

e) Desconocimiento de la autonomila de las grupos intermedios

16. La decisión de la Corte Suprema en el recurso interpuesto por Gasman Castro2s, en cuanto declara la inaplicabilidad del articulo 40 N9 10 de la ley 18.045 sobre mercado de valores por oponerse al artculo 19, inc. 39 de la Constitución, puede llegar a representar uno de los hitos más significativos de la jurisprudencia de la Córte en materia de control de constitucionalidad de las leyes. Ello dependerá de la aplicación que se haga en el futuro, en esta carea, del principio

que un mismo precepto legal se deciarb Inaplicable por tres vicios de fondo distintos, en Neltume resolvio "que habiéndose acogido el recurso por uno de sus fundamentos, no se hacen consideraciones y se omite el pronuncinmiento respecto de los otros capitulos en que se basa el referido libelo relativamente a la inconstitucionalidad de fondo" (letra c) de la resolución).

Tru 314 (1985) 764, expecialmente copsideranda 3 a 7 . 
de autonomía de los grupos intermedios, que es la base de la institucionalidad consagrada en el precepto constitucional antes citado y cuya vulneración por el artículo 40 No 10 de la ley 18.045 motivó su inaplicabilidad.

El artículo 39, inc. 19 de la Constitución, establece que "el Estado reconoce y ampara a los grupos intermedios a través de los cuales se organiza y estructura la sociedad y les garantiza la adecuada autonomía para cumplir sus propios fines específicos". El punto clave, entonces, para determinar el ámbito de la autonomía que la Constitución garantiza a cada grupo es la precisión de cuáles son sus fines específicos.

Esta precisión, según el fallo en análisis, no depende sólo de lo que la ley pertinente señale para el respectivo grupo intermedio, sino también de lo que sus integrantes decidan. "Es evidente-razona ia Corte- que el principal fin propio de ese grupo intermedio, sociedad comercial, es lograr metas económicas, y si este fin no lo consulta la ley, puede el propio grupo proponérselo insertándolo en sus Estatutos, Escrituras o Acuerdos, y ejerciendo así la autonomía que la Constitución le reconoce y ampara y que es fin esencial de todo organismo que persigue metas lucrativas" (considerando 6?).

EI artículo 40 No 10 de la ley 18.045, al limitar el beneficio que las Bolsas pueden proporcionar a sus miembros, señala que "consiste exclusivamente en posibilitarles el ejercicio de la función de corredores de las mismas". La disposición, al impedir el reparto de dividendos, "priva al grupo intermedio llamado Bolsa de Valores de la realización como entidadad de sus metas económicas que son en verdad sus fines propios y especificos y por consiguiente atenta contra la autonomía del grupo y contraviene, por tanto, el artículo 10 inciso 39 de la Constitución Política del Estado". (Considerando 79).

El reconocimiento de que la voluntad de los integrantes de un grupo es apta para determinar sus fines específicos, significa un refuerzo importantísimo para la autonomía de los grupos intermedios. Sin embargo, no debe extraerse -a nuestro juicio- del fallo de la Corte Suprema la conclusión que los miembros de un grupo tienen una libertad sin límites para fijar el fin específico del mismo, sino que esta libertad está en relación con la clase de grupo de que se trata. Por ello es que tratándose de una sociedad comercial, caso de la Bolsa de Valores, sus miembros podrán legítimamente perseguir el re- 
parto de utilidades.' Distinta serta la conclusion a la finalidad perseguida no resultara congruente con el tipo o clase de sociedad a que pertenexce el grupo que se organiz.

\section{CON C L U I I N Es}

16. Aunque el periodo objeto de estudio y el número de decisiones emanadas de la Corte Suprema no permiten formular conclusiones definitivas, de modo más bien provisional que podrá ser ratificado o rectificado por las futuras decisiones de aquella, pueden indicarse algunos puntos significativos.

La mayoría de la Corte ha mantenido el criterio tradicional que permite apreciar vía recurso de inaplicabilidad soblo la oposición que se da entre la Constitución y un precepto legal cuando éste es posterior a aquélla, aunque con algunos correctivos que han permitido ampliar el śmbito de este control de constitucionalidad a ciertos supuestos de leyes anteriores a la Constitución de 1980. Sin embargo, para la generalidad de los casos de leyes previas a la Constitución que resulten opuestas a la misma, se ha reafirmado la posición que ve en ello únicamente un problema de derogación de leyes, enfoque que puede resultar insuficiente para obtener una real supremacta constitucional atendidas las dificultades particulares que plantea la derogación tácita de las leyes por disposiciones constitucionales posteriores y la reticencia previsible de los jueces a admitirla.

Igualmente, la Corte Suprema no ha alterado su doctrina que rechaza la consideráción de vicios de forma para declarar la inaplicabilidad de los preceptos legales. Se señaló en el punto correspondiente, por lo que sólo cabe recordarlo aquí, cómo este planteamiento deja sin resolver problemas importantes relativos a la clase de ley que es adecuado dictar para regular determinadas materias.

En cuanto a las dispoticiones constitucionales que han servido a la Corte para fundamentar declaraciones de inaplicabilidad a partir de 1981, es todavia escaso el número de ellas que han sido utilizadas con este propósito. Dentro de las mismas, debe destacarse la garantía del derecho de propiedad que, por una parte, ha permitido a la Corte 
Suprema mantener la protección de la propiedad sobre derechos adquiridos y, por otra, proyectar la tutela del derecho de propiedad a aspectos particulares de éste. Resalta, también, la consideración novedosa de la igualdad ante la ley y, muy especialmente, la de la autonomía de los grupos intermedios, que permiten apreciar la amplitud con que el actual texto constitucional hace posible proteger los derechos de personas y grupos. 